\title{
EDITORIAL
}

\section{PERIÓDICOS EM EDUCAÇÃO FÍSICA CIÊNCIAS DO ESPORTE: UMA QUESTÃO PARA TODOS}

Este último número de 2012 da RBCE é também a derradeira edição em papel. A partir de 2013 ela será publicada apenas em versão online, acompanhando uma tendência geral dos periódicos científicos. Desde 2007, quando o CBCE completou 30 anos de existência, a revista vinha aparecendo nos dois formatos. Já digitalizáramos uma parte grande do acervo da RBCE, processo que, no entanto, ainda demandará algum tempo até sua conclusão. Otimização de recursos e a clareza de que as consultas ao periódico acontecem basicamente em sua versão digital, muitas vezes por meio da base SciELO, determinaram nossa decisão, que faz eco a certo consenso entre pesquisadores. Cumpre-se mais uma etapa na vida de um periódico científico.

Se a publicação em papel é assunto que já encontrou seu termo, não é o caso do financiamento das revistas científicas, reiterado vários vezes neste espaço editorial. A RBCE contou, em 20 I2, com o apoio do Conselho Nacional de Desenvolvimento Científico e Tecnológico (CNPq), contemplada que foi, pela primeira vez, em seu edital de editoração científica. Lamentavelmente, esse suporte sofreu descontinuidade, uma vez que, apesar de a revista ter avançado em relação aos anos anteriores, não tivemos o mesmo êxito no edital para 20 I3. Tampouco a base SciELO teve renovado os recursos que desde 2002 vinha recebendo do CNPq.

Coloca-se o desafio de seguir buscando recursos para avançar no projeto editorial da revista, que exige mais dinamismo em sua tarefa de promoção das 
pesquisas, por meio de sua divulgação, da área de Educação Física/Ciências do Esporte. O fortalecimento do Colégio Brasileiro de Ciências do Esporte, do qual a RBCE é um órgão, é fundamental neste processo, de maneira que é muito importante que pesquisadores e pesquisadoras o apoiem, fazendo dele sua entidade representativa. Como já nos manifestamos outras vezes, a discussão deve estar isenta de preconceitos e mirar as condições de possibilidade de manutenção e crescimento dos periódicos, algo do interesse de todo o campo da Educação Física/ Ciências do Esporte.

Este número da RBCE, como de costume, apresenta artigos muito variados, expressão da diversidade temática e epistemológica da área. Ele está constituído de I 5 artigos originais, 8 resultados de pesquisas no âmbito dos estudos Sócio-Culturais e Pedagógicos da Educação Física e 7 decorrentes de investigações no âmbito das Ciências Naturais. $\bigcirc$ primeiro deles, assinado por conhecido autor francês e por importante pesquisadora brasileira, analisa, a partir de um acervo constituído por 342 manuais escolares franceses de moral e de higiene, como se constitui um biopoder ou um micropoder no âmbito do discurso escolar. O segundo, de uma colaboradora da Colômbia, discute a motricidade como experiência corporal para com ela estabelecer uma relação com a educação. $\bigcirc$ artigo seguinte tem como foco a Educação Física escolar e oferece uma análise do planejamento curricular da disciplina com a finalidade de identificar sua organização e práticas pedagógicas no projeto "Acelerar para Vencer". O quarto e o quinto artigos tratam, a partir de distintos pontos de vista, da formação em Educação Física Escolar: um investiga como se articulam os elementos que contribuem para a formação política de professores da área engajados em diferentes instituições em que esta formação acontece; o outro focaliza a formação continuada, levando em consideração os entendimentos e as vivências dos professores de Educação Física no contexto do Governo Estadual do RS, gestão 2007-20 I 0, e as diretrizes nacionais e estaduais que orientam a disciplina. $\bigcirc$ trabalho docente no ensino superior, no campo da Educação Física, é objeto do sexto artigo, fruto de uma colaboração entre pesquisadores brasileiros e portugueses e resultado de uma investigação pautada por orientação hermenêutica, desenvolvida no contexto da UFSC e da UNOCHAPECÓ. O sétimo artigo problematiza os balanços de saberes e questionários de 585 alunos da quarta série de 15 escolas da rede pública de Florianópolis-SC, objetivando compreender os sentidos atribuídos às práticas corporais aprendidas fora da escola. Trata-se de trabalho em que colaboram dois dos membros da equipe editorial da RBCE, algo novo nos termos da experiência desta gestão, mas em consonância com a dinâmica da pesquisa e sua divulgação na Educação Física/Ciências do Esporte. O oitavo artigo comparou a identidade de gênero/sexo autopercebida e autoquantificada de atletas de diferentes modalidades. 
Universitários foram sujeitos nas pesquisas dos dois estudos que abrem, nesta edição, os artigos oriundos das Ciências Naturais. No primeiro deles, investigou-se os efeitos do estabelecimento de metas de curto e longo prazo na aprendizagem do arremesso de dardo de salão; no segundo, avaliou-se o nível de atividade física em acadêmicos de Medicina. A terceira idade é tema dos dois artigos seguintes: um que objetivou identificar motivos pelos quais idosos de Pelotas aderem a programas de atividade física; outro que verificou a associação entre a força muscular isocinética da musculatura extensora do joelho do membro dominante com a massa magra de diferentes segmentos corporais, em mulheres idosas. Atletas de futebol de campo, em situação real de treinamento, foram sujeitos do estudo sobre o efeito de uma suplementação com carboidratos e bebidas esportivas sobre parâmetros laboratoriais. Mais dois artigos originais compõem a edição. Num deles, avaliou-se os efeitos de correntes (CRT) na altura e tempo de voo do salto vertical com contramovimento (CMJ). No outro, o único artigo a trabalhar com modelo animal, os autores avaliaram a corrente de alta voltagem sobre o trofismo de sóleos de ratos Wistar com compressão de nervo isquiático. Encerramos este número da RBCE com uma resenha do livro "O esporte pode tudo".

Boa leitura!

Florianópolis, Vitória, dezembro de 2012. Alexandre Fernandez Vaz Felipe Quintão de Almeida Jaison José Bassani 